Humor als Formkonzept in der Musik Gustav Mahlers 
Mirjam Schadendorf

\section{Humor als Formkonzept in der Musik Gustav Mahlers}

Verlag J. B. Metzler

Stuttgart - Weimar 
Die Wiedergabe der Notenzitate erfolgt mit freundlicher Genehmigung der Verlage B. Schott's Söhne, Mainz, Peters, Frankfurt a.M./Leipzig und Universal Edition, Wien.

Zugl. Freiburg (Breisgau), Univ., Diss., 1993 D25

Die Deutsche Bibliothek - CIP-Einheitsaufnahme

Schadendorf, Mirjam:

Humor als Formkonzept in der Musik Gustav Mahlers / Mirjam Schadendorf - Stuttgart ;

Weimar ; Metzler, 1995

Zugl. Freiburg (Breisgau), Univ. Diss. 1993

ISBN 978-3-476-01291-3

ISBN 978-3-476-01291-3

ISBN 978-3-476-03586-8 (eBook)

DOI $10.1007 / 978-3-476-03586-8$

Dieses Werk einschließlich aller seiner Teile ist urheberrechtlich geschützt. Jede Verwertung außerhalb der engen Grenzen des Urheberrechtsgesetzes ist ohne Zustimmung des Verlages unzulässig und strafbar. Das gilt insbesondere für Vervielfältigungen, Übersetzungen, Mikroverfilmungen und die Einspeicherung und Verarbeitung in elektronischen Systemen.

(C) 1995 Springer-Verlag GmbH Deutschland

Ursprünglich erschienen bei J. B. Metzlersche Verlagsbuchhandlung und Carl Ernst Poeschel Verlag GmbH in Stuttgart 1995 


\section{Inhaltsverzeichnis}

\section{Humor als Formkonzept in der Musik Gustav Mahlers}

I. Einleitung 1

\section{Voraussetzungen}

»Musikalischer Humor« im 19. Jahrhundert

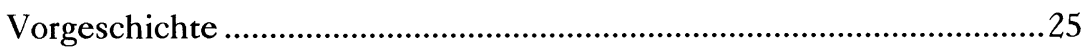

Der Auslöser: Jean Paul und Beethovens Eroica ……………………....28



Erste Digression: Bedingungen »dichterischen Humors «............................39

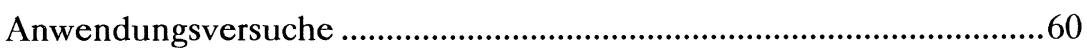

Zweite Digression: Formen »dichterischen Humors «...................................69

Die erste Komposition: Schumanns Humoreske .........................................8

Schattendasein: Die zweite Hälfte des Jahrhunderts ..............................98

Gustav Mahler: Symphonische Humoresken............................................100

Der analytische Zugang zum »musikalischen Humor»

Die ästhetische Kategorie des Humors .....................................................115

Humor als Gegenstand der Analyse .......................................................122

Humor und das Werk Gustav Mahlers ....................................................131 
III. Analysen

»Das himmlische Leben« (4. Satz der IV. Symphonie)

$\gg$ Volkston« und Orchesterlied

»Wiederholung «, »Entwicklung « und »Fortschritt « -

Formkonzepte im Orchesterlied.

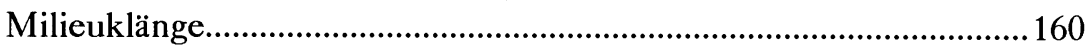

Humoristische Formkonzeption .............................................................. 168

Die »Fischpredigt« (3. Satz der II. Symphonie) .........................................180

Instrumentale und liedhafte Strukturen:

Die Strophe als Satz

Entwicklung im Scherzo:

Kreisbewegung und humoristische Schlußbildung.....

Fortschritt in den Trioeinschüben:

Einebnung des Milieuklangs

Das » Tierstück « (3. Satz der III. Symphonie) ..........................................216

Milieuklänge im Tierstück: Vogelrufmotive............................................218

Vogelrufmotivik

als konstruktiver Bestandteil der Liedexposition

Zersetzung des Liedes:

Entwicklung und Fortschritt der Vogelrufmotive

Vogelrufmotivik und Formverlauf -

Idyllische und katastrophische Naturdarstellung.

Humoristische Formkonzeption: Das Lied in der Symphonie

Nachwort

Anhang

Notenausgaben

Literaturverzeichnis 
»Wir möchten gerne die Welle kennen, auf welcher wir im Ozean treiben, allein wir sind diese Welle selbst.«

Jacob Burckhardt 